Relations industrielles

Industrial Relations

\title{
Combien vaut notre entreprise?, par André Barnay et Georges Callba, Entreprise Moderne d'Édition, Paris, 1968.
}

Paul Guy

Volume 23, numéro 3, 1968

URI : https://id.erudit.org/iderudit/027940ar

DOI : https://doi.org/10.7202/027940ar

Aller au sommaire du numéro

Éditeur(s)

Département des relations industrielles de l'Université Laval

ISSN

0034-379X (imprimé)

1703-8138 (numérique)

Découvrir la revue

Citer ce compte rendu

Guy, P. (1968). Compte rendu de [Combien vaut notre entreprise?, par André Barnay et Georges Calba, Entreprise Moderne d'Édition, Paris, 1968.] Relations industrielles / Industrial Relations, 23(3), 521-521.

https://doi.org/10.7202/027940ar

Tous droits réservés (C) Département des relations industrielles de l'Université Laval, 1968
Ce document est protégé par la loi sur le droit d'auteur. L'utilisation des services d'Érudit (y compris la reproduction) est assujettie à sa politique d'utilisation que vous pouvez consulter en ligne.

https://apropos.erudit.org/fr/usagers/politique-dutilisation/ 
le problème de la définition et du rôle des programmes d'emplois compensatoires à partir des diverses conceptions du sujet. Dans un deuxième temps, l'auteur traite d'abord des caractéristiques des ressources nécessaires ò de tels programmes et des contraintes techniques existantes. II passe ensuite à la mise en oeuvre des programmes d'emplois compensatoires et souligne les contraintes institutionnelles contre lesquelles it fout lutter. L'auteur termine son étude en discutant de la place de ces programmes dans une politique économique nationale et de leurs incidences sur les autres objectifs nationoux.

Cette version abrégée donne une excellente vue d'ensemble du problème, mais demande, par contre, d'être lue avec beaucoup d'attention.

\section{Pierre DIONNE}

Conseil pour les groupes spéciaux, par Gertrude Williams, O.C.D.E., Paris, 1967, 127 pages.

La présente étude est destinée à déterminer s'il est possible d'accroître la productivité de la main-d'oeuvre en réduisant le chômage à long terme et en dissuadant les travailleurs de changer trop fréquemment d'emplois, au moyen de l'organisation des conseillers spéciaux. En effet, l'objet de l'étude est d'examiner le rôle que peut jouer le service de l'emploi pour aider les chômeurs à long terme et les travailleurs changeant fréquemment d'emploi. D'autre part, I'ouvrage est basé sur l'hypothèse que le Service de l'emploi pourrait être chargé de dépister, d'interviewer et de conseiller les personnes depuis longtemps en chômage puisqu'il est le point de rencontre des travailleurs en quête d'emploi et de ceux qui ont été invités ò s'adresser à lui par d'autres organismes. L'auteur traite tour à tour du réemploi des cas difficiles, du rôle des conseils pour le placement des cas spéciaux, du service de l'emploi versus les servires sociaux, de la consultation, et du contrôle des résultats avant d'affirmer, en conclusion, la nécessité des services spéciaux de consultation. Tous les responsables des Services de l'emploi (ou Bureau de placement) auraient avantage à lire cette étude.

\section{Pierre DIONNE}

Combien vaut notre entreprise?, par André Barnay et Georges Calba, Entreprise Moderne d'Edition, Poris, 1968.

$\mathrm{Ce}$ livre se veut une revue des diverses méthodes d'évaluation des experts et de leurs principes sous-jacents. Ajoutons de suite que l'expert lui-même n'apprendra à peu près rien de neuf, sinon la simplicité. Cet ouvrage, en effet, s'adresse aux noninitiés, aux non-spécialistes qui s'affolent devant la kyrielle des solutions proposées. André Barnay et Georges Calba écrivent: "Plus praticiens que théoriciens, notre ambition n'a pas été de faire oeuvre savante mais de jeter un peu de clarté sur ce sujet difficile $\gg$.

La première section s'attarde à la notion générale de l'évaluation. Quelle en est le but? Quelles en sont les valeurs? En quoi consistent les principales phases de l'expertise? II faudra d'abord chercher à connaître l'entreprise elle-même: sa rentabilité, sa structure, son bilan, sa politique financière, ses besoins. La deuxième partie de ce livre s'avèrera peut-être la plus utile pour nos chefs d'entreprise: il s'agit de la pratique de l'évaluation. Comment déterminer l'actif net réel, la valeur substantielle, le rendement financier? Autant de questions, autant de réponses claires et précises. Avec ces nombreux tableaux et ces nombreux exemples chiffrés, cet ouvrage apportera sans aucun doute plus de lumière sur les principes et les méthodes d'expertise les plus couramment utilisés.

\section{Paul GUY}

La conciliation des conflits collectifs du travail en Belgique, par Eliane Vogel-Polsky avec le concours du Centre national de sociologie du droit social, Editions J. Duculot - S.A. Gembloux, Bruxelles, 1966,215 pages.

Tout au long de cet ourrage, l'auteur souligne la complexité des institutions, des techniques et des solutions destinées à résoudre pacifiquement les conflits collectifs du travail.

La première partie de l'étude procède à l'analyse des méthodes les plus usuelles de règlement pacifique des conflits collectifs du travail. L'auteur souligne l'importance du contexte socio-économique pour l'étude des systèmes de prévention des conflits et relève la dualité des procédures officielles et volontaires. Après avoir parcouru les étapes historiques de la solution pacifique des con- 